\title{
Do saber "natural" ao saber elaborado: possibilidades via objetos geradores
}

\section{From "natural" knowledge to elaborate knowledge: possibilities via generator objects}

\author{
Luiz Fernando Pires* \\ Carlos Henrique Pires**
}

\begin{abstract}
RESUMO
Durante os últimos anos muito se tem discutido sobre novas tendências metodológicas para o Ensino Médio. Entre as várias concepções está a utilização de objetos geradores. Este artigo tem por objetivo apresentar uma forma de como se trabalhar esta abordagem, priorizando o processo dialógico como um agente mediador para a construção do saber científico. Palavras-chave: ensino de física; objetos geradores, processo dialógico.
\end{abstract}

\begin{abstract}
During the last years many discussions have occurred about the new methodological tendencies in the high school. One of the several conceptions utilizes generator objects. This article presents a manner to work with this conception, emphasizing the dialogical process as a mediating agent for the construction of scientific knowledge.

Key-words: physics teaching; generator objects; dialogical process.

* Doutorando e Mestre em Ciências pela Universidade de São Paulo. Endereço eletrônico:

** Professor de Física e Matemática da Rede publica e privada de Educação. E-mail:
\end{abstract} lfpires@cena.usp.br chpires@hotmail.com- 


\section{INTRODUÇÃO}

Durante os últimos anos tem-se discutido muito sobre possibilidades de como se trabalhar a ciência no espaço escolar. Entre algumas propostas, estão a utilização de "ciência e cotidiano", "ciência, tecnologia e sociedade", "história e filosofia da ciência", "novas tecnologias" etc. [1].

Discutir temas referentes a ciência e tecnologia são importantes para que o educando incorpore os conhecimentos científicos e tecnológicos tão presentes em nossas vidas na atualidade [2]. O advento de novas tecnologias tem ocasionado o surgimento de novas formas de pensar, de agir e se relacionar comunicativamente, provocando mudanças nos comportamentos pessoais e sociais [2,3]. Acompanhar o desenvolvimento tecnológico, hoje, se faz necessário para poder preparar cidadãos para um mundo em rápida e surpreendente transformação.

O espaço escolar é onde se constrói o saber elaborado, aquele sistematizado por homens e mulheres por intermédio da ciência e tecnologia ao longo do processo histórico-cultural. É na escola que o ser humano irá trabalhar suas impressões do mundo e apropriar-se do saber metódico, sistemático, científico [4].

É fundamental durante a realização da atividade educacional que surja o processo dialógico $[5,6]$, no qual o educador, atuando como agente problematizador, busca gerar instabilidades no educando e colocar em confronto o saber espontâneo, "natural", assistemático [4] e o novo saber que se constrói [7].

Desta forma, é preciso arranjar mecanismos que possam realizar a transição do saber "natural" para o saber elaborado, e a utilização de objetos geradores pode ser um meio para alcançar tal objetivo. Objetos geradores são definidos como aqueles com potencialidades de facilitar o desenvolvimento do programa educacional [8]. Como exemplos de objetos geradores, pode-se citar imagens, objetos do cotidiano, equipamentos tecnológicos etc. A utilização de tais objetos é útil para o desenvolvimento do diálogo na sala de aula e pode contribuir para que o educando se aproprie de um determinado conhecimento científico e tecnológico, necessários para sua alfabetização técnica [9, 10] e busca da autonomia [11]. Um exemplo pode fornecer uma melhor visualização do uso destes objetos. Suponha que um educador da área de matemática necessite introduzir o conceito de progressões geométricas aos seus educandos. Uma maneira como isso poderia ser feito é pela introdução direta dos conceitos a partir de um livro; outra, seria utilizando um objeto 
gerador, por exemplo, um violão - devido ao fato de que tal instrumento possui a característica de que as distâncias dos seus trastos até um ponto fixo formarem uma seqüência matemática conhecida como progressão geométrica. Por meio de medidas e conseqüente observação de regularidades nas distâncias dos trastos nesse instrumento, os educandos poderiam ser introduzidos de uma maneira concreta ao conceito de progressões geométricas. Dessa forma, tal instrumento (que passa a ser um objeto gerador) se torna um facilitador do desenvolvimento do programa educacional, que, nesse caso, é o estudo de progressões geométricas na disciplina de matemática.

É importante que o objeto gerador seja de domínio de ambas as partes, educador e educando [8] e por intermédio de questionamentos sobre seu funcionamento, função social, formas de produção, questões éticas e históricas etc., pode ser possível alcançar a compreensão de um determinado tema em seus mais variados aspectos.

Os objetos geradores são facilitadores no aparecimento de quatro etapas básicas na transição do saber natural ao saber elaborado [12]. A primeira envolve a sondagem, quando o educador irá captar o saber que o educando possui sobre um tema, impressões que traz de seu cotidiano etc. A segunda envolve a problematização, quando ocorrerá o processo de "desequilíbrio" cognitivo pelo qual serão gerados desafios que irão despertar no educando motivação a querer saber mais sobre o conteúdo em estudo. A terceira envolve a sistematização do conhecimento, quando serão organizadas as informações que já existiam e as novas construídas pelo processo dialógico. A quarta envolve a generalização e aplicação dos conhecimentos assimilados quando o educando consegue relacionar o que aprendeu com situações de sua realidade. No entanto, o objeto gerador não precisa necessariamente estar presente em todas as quatro etapas, a sua utilização dependerá de como os educandos estarão reagindo a cada uma das etapas. Inicialmente, o objetivo do objeto gerador é ocasionar o "desequilíbrio" cognitivo e atuar como um provocador, de forma a motivar o educando a querer saber mais.

\section{Utilizando um objeto gerador}

Como exemplo de utilização de um objeto gerador propomos o uso de uma imagem (figura 1) cujo objetivo será trabalhar o tema aspectos éticos do uso da energia nuclear. 
Escolhemos a temática energia pela sua relevância no mundo em que vivemos nos mais variados aspectos: político, social, econômico, ecológico etc.

FIGURA 1. Protesto na Usina Nuclear de Bohunice em 1991 na ExTchecoslováquia [13].

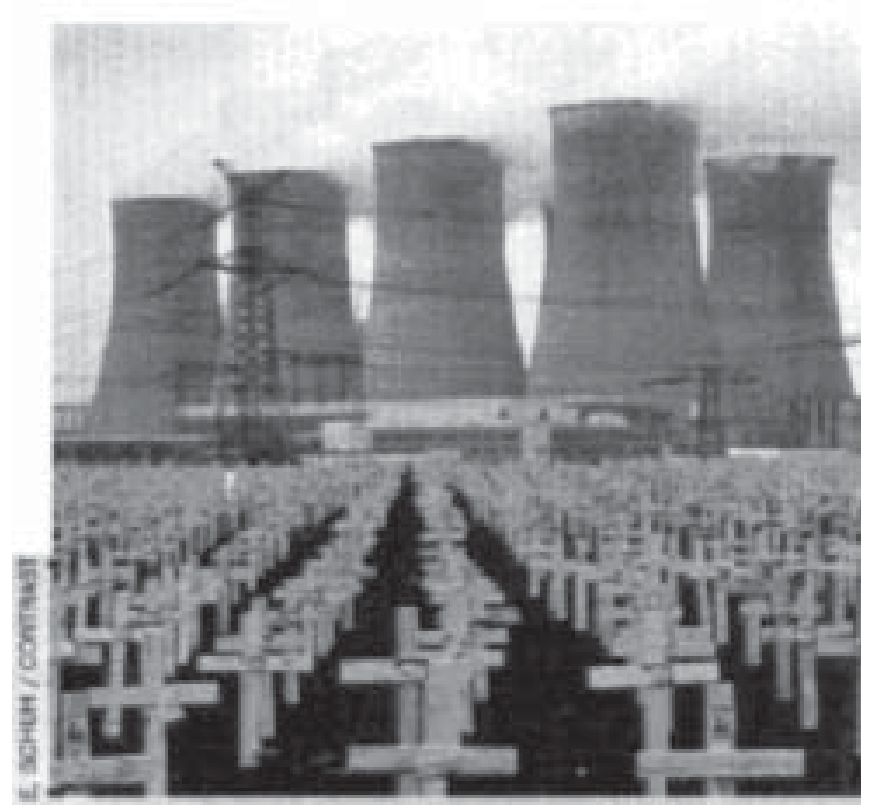

A escolha da imagem (objeto gerador) tem como critério o seu potencial de iniciar o tema proposto. A prática se inicia no momento em que a imagem é apresentada aos educandos como um agente polemizador. Ao observarem a figura surgirão os primeiros questionamentos dos quais podem aparecer as mais diversas respostas, sendo que algumas associarão a imagem a uma fábrica, ou a um cemitério, ou a um protesto, ou a uma usina de energia elétrica etc. É nesse momento que se inicia o processo dialógico entre educador e educando buscando a percepção do que a imagem representa, no caso, um protesto. É nessa etapa que os educandos se questionarão sobre os motivos do protesto e qual sua relação com uma usina nuclear. É a partir dessa fase que o tema proposto pode ser iniciado. 
A primeira etapa da prática envolve a sondagem, pela qual o educador obterá informações sobre o saber natural dos educandos. Isso pode ser alcançado por meio de perguntas dos educandos que mostrarão seus conhecimentos sobre formas de produção de energia, radioatividade, energia nuclear, usinas nucleares, acidentes radioativos etc. Por exemplo, alguns poderão citar que já ouviram falar do acidente radioativo de Goiânia ${ }^{1}$; outros, que viram na televisão que a usina nuclear de Chernobyl $^{2}$ somente após alguns anos do acidente é que foi desativada. Desta forma, como o educador poderá trabalhar com essas questões? Uma possibilidade seria questionar os educandos sobre o que entendem por radioatividade e qual a relação entre radioatividade e energia nuclear, ou ainda, se a energia nuclear pode ser perigosa.

A próxima etapa é a problematização, onde o saber "natural" começará a ser confrontado com um novo saber, surgindo o conflito cognitivo. E como o educador conduzirá essa etapa? Ele deverá fornecer subsídios para que o grupo se aproprie do tema proposto. Isto pode ser feito por meio de discussões utilizando-se artigos de revistas, da internet, de enciclopédias, de livros, de entrevistas com profissionais da área quando possível, de vídeos etc. ${ }^{3}$. Por exemplo, um conceito fundamental para o educando é o de radioatividade. $\mathrm{O}$ estudo desse conceito pode ser feito por meio de um vídeo que retrate situações ilustrativas demonstrando o decaimento de materiais radioativos ou de um livro texto ${ }^{4}$. No entanto, é importante que o processo dialógico esteja sempre presente durante toda essa fase. No final da problematização o educando deverá ter se apropriado dos conceitos básicos relacionados ao tema proposto, ou seja, terá obtido o conhecimento científico sobre energia nuclear, formas de produção, funcionamento básico de uma usina nuclear, lixo radioativo etc.

1 Em setembro de 1987, a violação, por dois catadores de papel, de um cilindro metálico contendo cesio-137 - que fazia parte de um equipamento de radioterapia abandonado em um ferro velho - causou o maior acidente nuclear da história do Brasil [17].

2 A explosão de um dos reatores da usina nuclear de Chernobyl (Ucrânia), em 1986, fez com que fossem liberados para a atmosfera cerca de 50 milhões de curies de material radioativo [17].

3 Procedimento semelhante pode ser encontrado no trabalho de PIRES (2002) ao utilizar a temática energia.

4 O educador pode utilizar páginas da internet como a da Associação Brasileira de Energia Nuclear (http://www.aben.com.br) ou ainda endereços educativos: http:// www.particleadventures.org (Física Moderna); http://physicsweb.org/TIPTOP/VLAB (Laboratório Virtual); http://www.labvirt.if.usp.br/institucional.asp (Laboratório Didático Virtual); http:// www.webelements.com (tabela periódica); http://www.psrc-online.org (sitio da Associação Americana dos Professores de Física), como fonte de apoio para o preparo das práticas. 
A sistematização é a etapa na qual o educando demonstra que houve uma superação do saber "natural", sendo esse substituído pelo saber elaborado. De que forma o educador poderá se certificar disto? O educador deverá criar situações que possibilitem aos educandos expor os saberes adquiridos na fase anterior. Isso pode ser feito por meio de seminários, painéis, confecção de artigos, construção de maquetes etc. Nessa fase deverá ocorrer o confronto entre os saberes que os educandos possuíam na sondagem e aqueles que passaram a ter. Para isso é importante que o educador tenha registrado as impressões que o grupo possuía durante a primeira etapa do processo (sondagem).

A última etapa envolve a generalização, na qual o tema inicialmente proposto será resgatado. Os educandos já possuem saberes que possibilitarão discutir sobre os aspectos éticos do uso da energia nuclear. Como o educador poderá realizar isto? Uma proposta, seria a simulação de um plebiscito sobre a possível implantação da Usina Nuclear de Angra III, por meio do qual os educandos deverão se posicionar a favor ou contra e fundamentar a sua resposta. Antes, é importante que sejam realizados debates com a formação de um grupo que irá se posicionar a favor do uso da energia nuclear e, outro, contra, sendo que a imagem utilizada como objeto gerador pode novamente ser usada para que os grupos emitam opiniões a respeito daquele protesto. Em outro momento, para não gerar tendências nos educandos, o educador pode sugerir que sejam invertidas as defesas, ou seja, quem era contra passa a ser a favor e vice-versa.

\section{Considerações finais}

Neste trabalho foi discutido o papel dos objetos geradores como facilitadores no desenvolvimento de quatro momentos que são fundamentais para a realização de uma prática que vise a construção do saber científico. A sondagem tem como objetivo fazer da sala de aula um espaço democrático que derrube o mito de que a ciência é de apropriação apenas do professor, e o aluno é apenas o ouvinte que não traz nenhum saber sobre o mundo onde vive. Esse tipo de educação que consiste na transmissão de conteúdos acabados, baseados na mera reprodução e memorização, demonstra uma prática educacional anti-dialógica e a serviço da dominação cultural [14]. A problematização é o processo de edificação do saber elaborado - mediado pelo diálogo - no qual um determinado conhecimento será construído e não 
apenas transmitido de um que sabe para aquele que nada sabe [15]. O papel do educador deve ser o do problematizador que, ao se encontrar dialogicamente com os educandos, irá proporcionar a ruptura causada pelo embate entre dois níveis de conhecimentos - o natural e o elaborado [16]. A sistematização e generalização se fazem necessárias para que haja a garantia de que o educando realmente se apropriou dos conhecimentos. É o momento no qual o educando - um ser inacabado e finito, por isso histórico - mostra ter alcançado a autonomia capaz de torná-lo realmente livre para assumir convicções e tomar decisões na sociedade em que vive, transformando-a e transformando-se [16].

A escolha dos objetos geradores deve estar o mais próximo possível de objetos reais que façam parte da realidade do educando, e o tema energia nuclear foi selecionado pela sua relevância no contexto mundial. Num mundo em que os recursos energéticos tradicionais são cada vez mais escassos, é necessário que o educando como cidadão tenha uma opinião consistente sobre as possíveis formas de energia que podem ser utilizadas. A energia nuclear é responsável por uma grande parcela da energia produzida no mundo e o Brasil, embora possua outros recursos energéticos, possui duas usinas nucleares e cogita-se a instalação de uma terceira [17]. Outra questão importante é o lixo nuclear.

Por intermédio da realização da prática sugerida neste artigo é possível alcançar a multidisciplinaridade, uma vez que o tema permite que várias áreas de conhecimento se relacionem. Segundo GUERRA et al. (1998), a proposta interdisciplinar pode ser concretizada basicamente sobre dois aspectos, ou por uma abordagem que privilegie a compreensão do processo de produção do conhecimento, ou, o que é mais comum, a partir de um tema gerador único que irá ser trabalhado pelas diferentes disciplinas. Por exemplo, quando se estudam os efeitos da radiação nos organismos, é preciso uma interação entre os educadores de diferentes áreas, como a Física, a Matemática, a Química e a Biologia. Quando aspectos éticos são discutidos, torna-se possível a interação com educadores da área de Filosofia, História, Geografia Política etc. ${ }^{5}$

Muitos trabalhos (DE MORAES et al., 1990; DELIZOICOV e ANGOTTI, 1992; AUTH et al., 1995; MION, 1995; CERVIERI, 1999) têm mostrado o potencial da utilização de objetos geradores como uma ferramenta importante para o ensino de Ciências e Física. Recentemente PIRES (2002), trabalhando com a temática energia, publicou um artigo mostrando o potencial da utilização de imagens como um dos meios para se alcançar a passagem do saber "natural" ao saber elaborado.

5 MOREIRA (2002) mostra uma forma de como a Física e a Literatura podem interagir atuando como facilitadores do ensino de Ciências. 
Portanto, uma educação sólida só poderá ser alcançada por intermédio de uma pedagogia que valorize o processo dialógico e a estruturação da autonomia, e uma forma de conseguir instaurar o diálogo para uma ação libertadora (FREIRE, 1983) é por meio da utilização de objetos geradores capazes de provocar a curiosidade nos educandos. No entanto, vale ressaltar que a proposta apresentada neste trabalho não possui a capacidade de prever possíveis dificuldades que surgirão durante a realização das quatro etapas pedagógicas. Muitas das dificuldades que poderão aparecer devido a própria natureza do processo dialógico, deverão ser contornadas pelo educador quando ocorrerem, e o fato do educador ter pensado a prática educacional lhe proporcionará subsídios para contornar tais dificuldades.

\section{NOTAS DE REFERÊNCIAS}

[1] MOREIRA, M. A. Ensino de Física no Brasil: retrospectiva e perspectivas. Revista Brasileira de Ensino de Física, São Carlos, v. 22, p. 94-99, 2000.

[2] MENEZES, L. C. Trabalho e visão de mundo: ciência e tecnologia na formação de professores. Revista Brasileira de Educação, São Paulo, n. 7, p. 75-81, 1998.

[3] KENSKI, V. M. O Ensino e os recursos didáticos em uma sociedade cheia de tecnologias. In: . Didática: O ensino e suas relações. Campinas: Papirus, 1996. p. 127-147.

[4] SAVIANI, D. Pedagogia histórico-crítica: primeiras aproximações. Campinas: Autores Associados, 1995.

[5] FREIRE, P. Pedagogia do oprimido. Rio de Janeiro: Paz e Terra, 1983.

[6] BASTOS, F. P. Alfabetização técnica na disciplina de Física: investigando como usá-la num curso de segundo grau. Florianópolis, 1990. Dissertação (Mestrado em Educação) - CED/PPGE, Universidade Federal de Santa Catarina.

[7] DELIZOICOV, D. N.; ANGOTTI, J. A. P. Metodologia do ensino de Ciências. São Paulo: Cortez, 1992.

[8] AUTH, M. A. et al. Prática educacional dialógica em física via equipamentos geradores. Caderno Catarinense de Ensino de Física, Florianópolis, v. 12, n. 1, p. 40-46, 1995.

[9] ANDERSON, S.; BAZIN, M. O cientista como alfabetizador técnico. In: Ciência e (in)dependencia. Lisboa: Horizonte, 1977. p. 94-98. 
[10] ANDERSON, S.; BAZIN, M. Ao lado dos trabalhadores chilenos: vivendo e ensinando a ciência para o povo. In: Ciência e (in)dependencia. Lisboa: Horizonte, 1977. p. 99-110.

[11] FREIRE, P. Pedagogia da autonomia. Rio de Janeiro: Paz e Terra, 1997.

[12] COLÉGIO PUERI DOMUS. Síntese de reunião de professores. São Paulo, 1996.

[13] SUPER INTERESSANTE. São Paulo: Abril, v. 11, n. 1, 1997. 35 p.

[14] FREIRE, P. Pedagogia do oprimido. Rio de Janeiro: Paz e Terra, 1983.

[15] BASTOS, F. P. Pesquisa - Ação emancipatória e prática educacional dialógica em Ciências Naturais. São Paulo, 1995. Tese (Doutorado em Educação) - Feusp, Universidade de São Paulo.

[16] MION, R. A. O diálogo enquanto mediação entre ensinar e aprender: uma análise prospectiva para o ensino de Física. In: PPGE/UFSM. Santa Maria: [s.n.], 1995. p. 1-14.

[17] HELENE, M. E. M. A radioatividade e o lixo nuclear. São Paulo: Scipione, 1996.

[18] GUERRA, A. et al. A interdisciplinaridade no ensino de ciências a partir de uma perspectiva histórico-filosófica. Caderno Catarinense de Ensino de Física, Florianópolis, v. 15, n. 1, p. 32-46, 1998.

[19] MOREIRA, I. C. Poesia na sala de aula de ciências? A literatura poética e possíveis usos didáticos. Física na Escola, v. 3, n. 1, p. 17-23, 2002.

[20] MORAES, A. G. et al. Representações sobre ciência e suas implicações para o ensino da Física. Caderno Catarinense de Ensino de Física, Florianópolis, v. 7, n. 2, p. $120-127,1990$.

[21] CERVIERI, R. L. Laboratório e os objetos geradores como incentivadores da dialogicidade no Ensino de Nível Médio. In: . Metodologia e Prática de Ensino de Física II. Ponta Grossa: [s.1.], 1999. p. 1-5.

[22] DELIZOICOV, D. N.; ANGOTTI, J. A. P. Física. São Paulo: Cortez, 1992.

[23] PIRES, L. F. Possibilidades do desenvolvimento de uma cultura científica no ensino de Física e sua relação com a carga horária atual. Revista de Ciência da Educação, Campo Largo, v. 1, n. 1, p. 1-14, 2002.

Texto recebido em 22 mai. 2002

Texto aprovado em 04 dez. 2002 